\title{
NIHILISMO Y ARTE DE LA VIDA. ENTRE MONTAIGNE Y NIETZSCHE
}

Herbert Frey*

RESUMEN: Nihilismo: falta de objetivo, de respuesta al por qué. En Nietzsche, el proceso violento de destrucción se transforma en una postura afirmativa, en arte de vida. El filósofo interioriza la influencia de Turguéniev y Dostoievsky, regresa a una comprensión del mundo pre-cristiana y propone la autocreación del hombre; encuentra en Montaigne su principal fuente de inspiración.

\section{yod}

ABSTRACT: Nihilism is devoid of objective and purpose. In Nietzsche's work, the violent process of destruction transforms into a positive stance, the art of living. He incorporates Turguenev and Dostoyevsky's influence, reverts back to the pre-Christian perception of the world, and promotes man's self-creation. Montaigne is his primary source of inspiration.

PALABRAS ClAVE: Nietzscche, Montaigne, nihilismo, arte de vida, auto-afirmación.

KEY WORDS: Nietzsche, Montaigne, nihilism, art of living, self-affirmation.

RECEPCIÓN: 18 de enero de 2011.

APROBACIÓN: 24 de mayo de 2011.

* Intituto de Investigaciones Sociales, UNAM. 
CITAM Derechos Reservados.

La reproducción total o parcial de este artículo se podrá hacer si el ITAM otorga la autorización previamente por escrito. 


\title{
NIHILISMO Y ARTE DE LA VIDA. ENTRE MONTAIGNE Y NIETZSCHE
}

\begin{abstract}
Con el transcurrir del tiempo, la humanidad ha tenido que soportar por parte de la ciencia dos grandes ofensas a su cándido amor propio. La primera, cuando se enteró de que nuestra tierra no es el centro del universo, sino sólo una minúscula partícula dentro de un sistema universal prácticamente inimaginable en su magnitud. Para nosotros, esta ofensa está vinculada con el nombre de Copérnico, aunque ya antes la ciencia alejandrina había proclamado algo similar. La segunda, cuando la investigación biológica destruyó la aparente superioridad del hombre dentro de la creación, remitió su origen al reino animal e hizo patente la insoslayable animalidad de su naturaleza. Bajo la influencia de Charles Darwin, Alfred R. Wallace y sus antecesores, este cambio de valores se ha consumado en nuestros días no sin la vigorosa resistencia de nuestros contemporáneos. Pero el afán humano de grandeza habrá de experimentar la tercera y más sensible de sus ofensas a través de la actual investigación psicológica, que pretende demostrarle al Yo que no es dueño y señor ni siquiera de sí mismo, sino que permanece sujeto a los indicios corporales de lo que sucede inconscientemente en su vida interior. ${ }^{1}$
\end{abstract}

Sigmund Freud hizo este planteamiento en las conferencias introductorias al psicoanálisis, llevadas a cabo entre 1915 y 1917, en una Viena cuyo brillo amenazaba con apagarse por el declive de la monarquía danubiana como centro del espíritu. Freud describía en este contexto,

${ }^{1}$ Sigmund Freud, Vorlesungen zur Einführung in die Psychoanalyse, 1969, Frankfurt, Fischer, Studienausgabe Band 1, p. 283. 
HERBERT FREY

el derrumbe de una visión tradicional del mundo que había imperado en Occidente durante dos mil años y que había sido socavada en sus cimientos por los avances de la ciencia, pero también por el proceso de la Ilustración europea.

En los años ochenta del siglo XIX, Nietzsche había diagnosticado este proceso como el ascenso del nihilismo:

Describo lo que viene: el ascenso del nihilismo. Lo puedo describir, porque aquí está ocurriendo algo inevitable -los signos de ello están por todas partes, pero todavía faltan los ojos para verlos. Ni elogio ni censuro que venga; creo que está en curso una de las mayores crisis, un momento de la más profunda autorreflexión del hombre; si éste logra recuperarse de ella, si logra dominar esta crisis, es una cuestión de fortaleza: es posible [...] a modo de prueba, el hombre moderno cree unas veces en un valor, otras veces en otro, y luego los desecha [...] Pero por fin se atreve a una crítica de los valores en general; descubre su origen; descubre lo suficiente como para no creer más en ningún valor; ahí está el pathos, el nuevo estremecimiento [...] Lo que aquí describo, es la historia de los próximos dos siglos. ${ }^{2}$

En La genealogía de la moral, Nietzsche coincide por adelantado con las tesis de Freud. "Desde Copérnico, el hombre parece haber caído sobre un plano inclinado - de ahí en adelante se aleja rodando cada vez con mayor velocidad del centro- ¿hacia dónde? ¿hacia la nada? ¿hacia el sentir taladrante de su propia nada?"3

La nada, la destrucción, el no ser son las metáforas centrales del nihilismo. Nietzsche lo calificó como el más inquietante de los huéspedes, y los literatos del fin del mundo lo dibujaron como un fantasma, como si el nihilismo fuera a significar el fin de todas las cosas.

Pero continuemos con Nietzsche. El filósofo alemán destacó una característica fundamental del nihilismo, sin que ésta agotara sus diversos significados. En los fragmentos póstumos de los años ochenta,

${ }^{2}$ Friedrich Nietzsche, Sämtliche Werke, 1980, München, hrsg. Giorgio Colli und Mazzino Montinari, Kritische Studienausgabe in 15 Bänden, dtv [KSA]: 12 Nov. 1887-Marzo 1888, 11 [119], pp. 56-7.

${ }^{3}$ KSA 5, GM §25, p. 404. 
Nietzsche dio la siguiente definición: "Nihilismo: falta el objetivo; falta la respuesta al porqué. ¿Qué significa nihilismo?-Que los valores supremos se desvalorizan [...] éste alcanza su máximo de energía relativa como violenta fuerza de destrucción: como nihilismo activo". ${ }^{4}$

Esta descripción del nihilismo como proceso violento de destrucción, de aniquilamiento de lo tradicional y de la costumbre; esta caricatura y fantasma de un concepto sigue errando hoy todavía por los pasillos de la filosofía. El nihilismo es para la filosofía lo que el demonio es para la Iglesia católica. En su libro de ensayos El hombre rebelde, Albert Camus también parece reafirmar esta interpretación del nihilismo cuando cita a Nietzsche. "Para erigir un nuevo santuario, hay que destruir un santuario; ésta es la ley". En su opinión, el que pretende ser creador en el bien y en el mal, primero tiene que ser destructor y romper valores. "Es decir, el sumo mal corresponde al sumo bien, pero el sumo bien es creador". 5

Aunque posteriormente asumió una posición afirmativa frente al nihilismo, en su apreciación catástrófica Nietzsche es obviamente un hijo de su tiempo. Como lo han demostrado investigaciones recientes, Nietzsche bosquejó su concepto de nihilismo en los años ochenta y lo desarrolló siguiendo a algunos literatos rusos. Las novelas de Turguéniev y Dostoyevski jugaron en este aspecto un papel central. Bazárov, el héroe de Padres e hijos de Turguéniev, representa a un tipo de nihilista que no se conforma con decir no, sino que quiere destruir y reformar cualquier tipo de autoridad.

Otra fuente importante de la que Nietzsche abrevó para su concepto de nihilismo fueron las novelas de Dostoyevski, al que conoció en los años 1886-87. De manera confiable se ha podido documentar que leyó Humillados y ofendidos, Memorias del subsuelo y Los endemoniados, de los cuales inclusive hizo apuntes. Su acercamiento con El idiota se introdujo en su propia estilización de la imagen de Cristo. Aparte de estas obras, sin embargo, no hay certeza de que Nietzsche haya leído también Crimen y castigo y Los hermanos Karamazov.

${ }^{4}$ KSA 12, Otoño de 1887, 9 [35], p. 350-1.

${ }^{5}$ Albert Camus, El hombre rebelde, 1953, p. 56. 
HERBERT FREY

En todo caso está claro que Nietzsche encontró en Dostoyevski a uno de sus últimos hermanos antagónicos. Estaba impresionado por la delicadeza psicológica de las obras de Dostoyevski y lo alababa como "el único psicólogo [...] del que he tenido algo que aprender: es uno de los encuentros más afortunados de mi vida". 6

Nietzsche y Dostoyevski, qué lejanía y cuánta cercanía. Ambos coinciden en el peso que le atribuyen a la "Muerte de Dios" y al "ya no poder creer” en el análisis de la desesperación contemporánea. Están de acuerdo en que con la "Muerte de Dios" se ha iniciado la época de la transvalorización de todos los valores; la época del "más allá del bien y del mal"; pero también la época en la cual el hombre, ahora único responsable de sí mismo, cae en el peligro de una desesperación antes inimaginable, dispuesto, según el caso, al homicidio o al suicidio; y, no de manera inconsciente, sino en pleno proceso de reflexión sobre la nueva libertad y los límites desaparecidos. Cada uno de los héroes de Dostoyevski es un hermano del superhombre, un hombre-dios al borde de la nada. Y sin embargo... qué diferencia. Por un lado, la esperanza de Dostoyevski en un especulativo Viernes Santo y en la renovación de la religión en el alma rusa; y por otro, la voluntad de Nietzsche de encontrar a través de todas los etapas del nihilismo no el regreso a la religión, sino la inédita afirmación de la existencia sin un dios.

Como nadie antes que él en la historia de la filosofía occidental, Nietzsche descubrió la relación que existía entre la interpretación de la historia a través del cristianismo y el surgimiento del nihilismo; y también fue uno de los primeros en comprender que, como representante del monoteísmo europeo, el cristianismo tenía que ser destruido para poder emprender una rehabilitación de la sensualidad, una reapropiación del mundo, el restablecimiento de una relación afirmativa con el universo que el monoteísmo había destruido.

La pregunta con la cual Nietzsche expone todas las interrogantes de la filosofía de un modo radicalmente moderno, es la pregunta sobre el sentido. Es el primero en utilizar literalmente la fórmula sobre el sentido de la vida; de este modo, el valor de la vida se convierte en uno de

${ }^{6} \mathrm{KSA} 6$, GD $\S 45$, p. 147. 
los temas centrales de su filosofía. En dos obras innovadoras, una sobre la Ilustración europea y otra titulada Poder y decisión, Panajotis Kondylis definió al nihilismo de la siguiente forma: "El nihilismo es la tesis de la carencia objetiva de valor y de sentido del mundo y del hombre". 7

Con ello, empero, no quería decir que no podían existir creaciones de valor y de sentido, sino sólo que las propiedades de valor del mundo y del hombre no estaban fundamentadas en sí mismas, sino en valoraciones subjetivas de los seres humanos. En este sentido, ya la Ilustración francesa había anticipado aspectos sustanciales del nihilismo nietzscheano. Porque el eje principal de la Ilustración era emancipar a la razón y a la sensualidad de autoridades irracionales y, con ello, arrebatarles el poder sobre la vida humana. Según Kondylis, el nihilismo de la Ilustración consistía en "llevar a cabo de una manera incesante y sin valorizaciones la rehabilitación de la sensualidad". ${ }^{8}$

Nietzsche subraya un momento sustancial del nihilismo: la comprensión de que no existen valores objetivos absolutos que hayan sido creados por un poder sobrenatural. Entiende así el carácter subjetivo de todas las creaciones de valor. Con ello, sin embargo, la interpretación subjetiva del hombre se convierte en una instancia que decide sobre el valor o no valor de la existencia; la simple voluntad práctica se torna en la generadora de todos los valores. Frente a una tradición que negaba y reprimía lo existente, el mundo y los instintos, Nietzsche fijó su postulado de la "transvalorización de todos los valores".

Nietzsche fue uno de los primeros en reconocer con plena conciencia la relación entre cristianismo y nihilismo, porque su nihilismo activo era tan sólo el último estadio de un proceso que tenía su fundamento en la historia de Occidente. El nihilismo tenía su origen -y con ello atribuía Nietzsche al cristianismo la invención del nihilismo-en la creación e imaginación de aquel Dios único del monoteísmo, representado por la tradición judeo-cristiana, que devaluó al mundo como cosmos y como orden, y que desplazó hacia un más allá el único sentido y valor

${ }^{7}$ Panajotis Kondylis, Die Aufklärung im Rahmen des neuzeitlichen Rationalismus, 1986, München/Stuttgart, dtv/Klett Cotta (M u. E, p. 124).

${ }^{8}$ Op. cit., p.490. 
de la existencia y del mundo. Nietzsche hablaba de una transvalorización de todos los valores, para regresar al mundo tal y como éste había existido antes de la invención y el establecimiento del monoteísmo. Sólo después de la separación entre Dios y el mundo este último podía parecer sin sentido, en tanto que el antiguo cosmos de griegos y romanos era divino en sí mismo. El nihilismo del judaísmo, y más tarde del cristianismo, consistía en despojar al mundo de su divinidad, y en demonizar y denunciar todos los impulsos de la carne y la sensualidad.

Nietzsche entendía a la religión monoteísta como nihilista precisamente porque había construido un sentido que se basaba en valoraciones puramente ficticias y, sólo a causa de ello, la destrucción de este sentido imaginario podía aparecer como nihilismo.

"Ha llegado el momento - expone Nietzsche en sus escritos póstumos de los años ochenta- en que tenemos que pagar por haber sido cristianos durante dos milenios: perdemos el eje gravitacional que nos permitía vivir [...] Nos precipitamos repentinamente hacia los valores opuestos, con la misma carga de energía que generó una sobrevaloración tan extrema del hombre en el hombre". 9

Precisamente por el hecho de que se había derrumbado una interpretación del mundo que hasta entonces había valido como absoluta, parecía que ahí en adelante ninguna otra interpretación del mundo fuera posible:

El nihilismo aparece ahora no porque el disgusto en torno de la existencia fuese mayor que antes, sino porque en general uno se ha vuelto receloso de que pueda haber un 'sentido' en la desgracia, en la existencia misma. Una interpretación feneció, pero como era la única posible, parecía entonces que la existencia no tendría ningún sentido, como si todo fuese en vano. ${ }^{10}$

Que los mismos hombres eran los creadores de este Dios que ahora ya no tenía validez, se desprende de la siguiente cita de Nietzsche: "iQué

${ }^{9} \mathrm{KSA}, 13$, p. 69.

${ }^{10} \mathrm{KSA} 12$, p. 212. 
maravilla!: El dios que alguna vez crearon de la nada, ahora se ha transformado para ellos en nada". "Entendía que la tradición del monoteísmo, nacida del judaísmo, producía una ficción al crear a aquel Dios Todopoderoso que prometía un sentido a la vida humana, siempre y cuando uno se sometiera a sus exigencias y mandatos. En esta construcción, Dios mismo era el que colocaba al hombre en el centro de su creación y quien velaba permanentemente por el bienestar de su creatura. Según el mito, este Dios se habría revelado a los hombres y les habría dado sus mandamientos eternos y absolutos, generando así una sacralización de la moral. La obediencia a Dios y a sus mandatos divinos era una exigencia, al tiempo que el pensamiento humano autónomo era estigmatizado como un pecado. En este orden del mundo, la soberbia y la lujuria eran pecados mortales porque implicaban que el hombre podía juzgar por sí mismo sobre el bien y el mal, y porque su apetito por el placer carnal lo ataba demasiado a la tierra como para poder lograr en ella su realización. El hombre sólo podía encontrar la bienaventuranza eterna en el más allá si se sometía a la imaginaria voluntad divina.

En uno de los pasajes más famosos del legado, el Lenzer Heide Fragment del 10 de junio de 1887, Nietzsche formuló bajo el título "El nihilismo europeo", una de la explicaciones más concisas sobre la creación de sentido cristiana y el nihilismo que derivó de ella.

¿Qué ventajas ofrecía la hipótesis moral cristiana?

1. Proporcionó al hombre un valor absoluto, en contratse con su pequeñez y contingencia en el incesante curso del nacer y el perecer.

2. Sirvió a los defensores de Dios, ya que al conferir al mundo un carácter de perfección pese al sufrimiento y a la desgracia -incluida aquella libertad- el mal parecía tener un sentido pleno.

3. Estableció una sabiduría en torno de valores absolutos [...]; impidió que el hombre, como hombre, se despreciara; que tomara partido contra la vida; que desesperara ante el conocimiento: era un medio de subsistencia; en suma: la moral era el gran antídoto contra el nihilismo práctico y teórico". ${ }^{12}$

\footnotetext{
${ }^{11} \mathrm{KSA} 11$, p. 403.
}

${ }^{12} \mathrm{KSA} 12$, p. 211. 
En el apartado diez del Lenzer Heide Fragment, Nietzsche se refirió por último a la pretensión del cristianismo de crear un sentido para los humillados y ofendidos, como los habría denominado Dostoyevski:

10. La moral protegió a los desventurados del nihilismo, en tanto que atribuyó a cada uno un valor infinito, un valor metafísico, y lo incluyó en un orden que no concordaba con el poder y la jerarquía terrenales: predicaba resignación, sumisión, etc. En caso de que la fe en esta moral se derrumbara, los desventurados ya no encontrarían consuelo y perecerían. $^{13}$

Hans Blumenberg, uno de los historiadores de las ideas más importantes de la Alemania de la posguerra, concordaba con Nietzsche en que se podía encontrar una estrecha relación entre el nihilismo y la historia del cristianismo. En su trascendente obra La legitimidad de la Época Moderna, llega a la conclusión de que ésta no dispone de medios para responder en forma adecuada a las grandes preguntas sobre Dios y el mundo heredadas de la Edad Media. No es posible llenar adecuadamente el horizonte de interrogantes heredado del medioevo cristiano. Entonces, surge la pregunta de cómo el hombre moderno puede superar esta situación histórica por sí mismo y reconciliado con el mundo. Blumenberg da a ello una respuesta original. Primero, constata que el cristianismo "introdujo nuevos planteamientos dentro del marco de las afirmaciones posibles y deseables sobre el mundo y el hombre". ${ }^{14}$

A estas creaciones de sentido pertenecen, por ejemplo, el enaltecimiento del hombre como rey y centro del mundo, la garantía de la participación de Dios en la suerte y el destino del hombre, y la revaloración del mundo como una creación cuidadosamente supervisada.

Para Blumenberg, sin embargo, estas interpretaciones del cristianismo son definiciones inapropiadas de la realidad. En cualquier caso, a lo largo de los siglos nos hemos acostumbrado tanto a las desmedidas creaciones de sentido del cristianismo, que con la desaparición de éste no desaparecen necesariamente al mismo tiempo sus respuestas.

${ }^{13}$ KSA 12 , p. 215.

${ }^{14}$ Hans Blumenberg, Die Legitimität der Neuzeit, 1988, Frankfurt, Suhrkamp, p. 74. 
De esta manera, los deseos y las esperanzas heredados parecen justificarse como algo natural. Sin embargo, en realidad fueron creados por el cristianismo y, por lo tanto, no se pueden justificar. El abdicante cristianismo hereda una necesidad de sentido tan inmensa como imposible de cubrir. Blumenberg habla de la "indigencia de una conciencia, primero sobredimensionada por las grandes preguntas y expectativas, $\mathrm{y}$ luego defraudada". ${ }^{15}$

La reivindicación absoluta de sentido de esta conciencia carece de razón, porque le exige a la realidad algo que es incapaz de dar. En estas circunstancias, el manejo adecuado para tal situación es única y exclusivamente el intento de desmontarlo. Esto sólo es posible mediante la disminución y moderación de la valoración del sentido.

En su innovador libro, Blumenberg ve en las ciencias naturales modernas sobre todo un recurso con cuya ayuda el hombre podría mantener a distancia y bajo control a la omnipotente naturaleza. Por el contrario, en La génesis del mundo copernicano, el autor destaca el otro lado del desarrollo de estas ciencias, es decir, que las ciencias naturales no sólo son un medio para domesticar a las fuerzas superiores de la naturaleza: también muestran con toda claridad el grado apabullante en que estas fuerzas no son domesticables. ${ }^{16}$

El eje rector de La génesis del mundo copernicano es el descubrimiento de una naturaleza omnipotente mediante de la investigación de las ciencias naturales. Al quedar destruido el papel preponderante del hombre en la tierra, simultáneamente se abre un proceso que tiende a concebir al universo como sin sentido y sin Dios. El mundo ha enmudecido ante la pregunta de cuál es, en última instancia, su propio sentido y el del hombre. Así que el hombre ahora está obligado a dirigir esta pregunta sólo a sí mismo.

De este modo, el conocimiento científico destruye la idea de la singularidad del ser humano, para replegarlo sobre sí mismo como último reducto. Mientras más evidente se torna que el mudo e inconmensurable mundo no se preocupa por el ser humano, con mayor fuerza

${ }^{15}$ Ibid., p. 98 .

${ }^{16} \mathrm{~V}$. Hans Blumenberg, Die Genesis der Kopernikanischen Welt, 1981, Frankfurt, Suhrkamp. 
HERBERT FREY

el interés del hombre debe dirigirse hacia sí mismo y su preocupación girar en torno de él. Así, la mirada humana retorna del universo a la tierra que es su hogar, para enfrentarse con un entorno poderoso y hostil. En este viraje hacia el mundo terrenal, Blumenberg vuelve a toparse con Nietzsche, quien había concebido a la tierra - es decir, al más acá- como la auténtica esfera de acción del hombre.

Que el curso de los astros -y con él también el de la tierra- no tiene ningún propósito $\mathrm{y}$, por lo tanto, tampoco persigue ningún objetivo, no es un motivo para que Nietzsche lo rechace; al contrario, el mundo terrenal se convierte en el único lugar donde el hombre puede realmente realizarse.

Por ello, también Nietzsche debe regresar a una comprensión del mundo como la que imperaba antes de la invención del monoteísmo judeo-cristiano; es decir, a la de la antigüedad greco-romana. Porque fue la Antigüedad la que supo ver la tragicidad de la existencia humana, la aceptó y, a pesar de ello, no cayó por esto en la desesperación.

"Recuperar la visión antigua del mundo. ¡La moira por encima de todo, los dioses representantes de las fuerzas reales! Volverse antiguo", ${ }^{17}$ escribió Nietzsche en sus apuntes de 1878.

Dos son probablemente los momentos que una filosofía del arte de la vida debe retomar de la Antigüedad. En primer lugar, la sentencia de Protágoras, que coloca al hombre como medida de todas las cosas. Pero este hombre no es el hombre en sus características generales, sino el hombre como individuo, con sus percepciones y emociones. Y Protágoras también introduce en la filosofía la idea de que la medida no es algo dado, prestablecido, sino que se sustenta en imposiciones, en el hombre como determinante y que, por ello, la medida es una cuestión de poder. La relatividad de la medida lleva a la decisión por medio del poder. ${ }^{18}$

En segundo lugar, las corrientes de la Antigüedad que más fuertemente influyeron en la teoría moderna del arte de la vida son las escuelas

${ }^{17} \mathrm{KSA} 8$, p. 507.

${ }^{18}$ H. Falk, (ed.), Panajotis Kondylis: Aufklärer ohne Mission, 2007, Berlin, Akademie Verlag, p. 55. 
filosóficas de la antigüedad tardía, que tuvieron su expresión en el epicureismo, el escepticismo y el estoicismo. La frase "reivindícate a ti mismo", es decir, el valor de la autorrealización, se encuentra en Séneca y puede considerarse como el elemento vinculante de todas estas corrientes filosóficas. La preocupación por uno mismo se convierte en el hilo conductor de un mundo que carece de normas generales. Cuando el hombre ya no se siente incluido en ningún contexto de sentido, entonces es el único responsable de trazarse objetivos y de inventarse a sí mismo.

La respuesta de Nietzsche al nihilismo es la autocreación del hombre, la transformación de la vida humana en una obra de arte. "Para qué está aquí la humanidad, para qué está aquí 'el hombre', eso no debe importarnos para nada. Pero pregúntate para qué estás tú aquí; y si no logras descubrirlo, entonces fíjate tú mismo metas y sucumbe por ellas. No conozco ningún mejor fin en la vida que el de sucumbir en aras de lo grande y lo imposible: animae magnae prodigus" ${ }^{19}$

En la estilización de la propia existencia, se hace también patente la perspectiva nietzscheana de la maestría estética. A partir de una disposición trágico-heroica se dota a sí mismo de una forma notable, en tanto que no sólo condensa los sufrimientos que le provoca su propia época, sino a la época misma. Todo ocurre con la pretensión del "gran estilo", para hacer de la vida misma una obra de arte. ${ }^{20}$

Este propósito probablemente se encuentra formulado de la manera más clara en La gaya ciencia: 'El uno es necesario - dar 'estilo' al propio carácter, un arte grande e infrecuente. Lo practica aquel que tiene una visión completa de todo lo que le ofrece su naturaleza en fortaleza y debilidad y luego las integra a un plan artístico, gracias al cual ambas se manifiestan como arte y razón, y aun la debilidad cautiva la mirada". ${ }^{21}$

"El uno es necesario" pretende establecer la necesidad de darse forma a uno mismo en lugar de creer en el Yo como un hecho consumado. Apunta hacia una estética de la existencia, no en el sentido de una teoría de la belleza, sino en el sentido de la autocreación. Esta auto-

\footnotetext{
${ }^{19} \mathrm{KSA} 7$, p. 651.

${ }^{20} \mathrm{KSA} 1$, p. 56.

${ }^{21} \mathrm{KSA} 3$, FW, p. 530.
} 
HERBERT FREY

creación no significa per se su logro: puede implicar también su fracaso. Como antiproyecto a la existencia determinada por la norma, la moral y la obligación, Nietzsche propone aprender de las formas de proceder y de las visiones originales de los artistas y trasladarlas a la vida: "Nosotros, empero, queremos ser los escritores de nuestra propia vida y, sobre todo, de lo más pequeño y cotidiano". ${ }^{22}$ La óptica del artista entraña el no manejar esta actividad con descuido, sino esforzarse por llegar a ser un maestro del propio oficio, "en lo que hace a cada habilidad y maestría". ${ }^{23}$

Para Nietzsche, la existencia no puede entenderse con las categorías de la moral: constituye en sí misma una especie de obra de arte. La estética del creador sirve entonces también para configurar la propia vida como una obra de arte.

Considera que este arte de la vida se fundamenta en la autoformación del individuo. Y aquí, de lo que se trata, es de darse una dirección a uno mismo en la lucha cotidiana. ${ }^{24}$ En este aspecto, Nietzsche tiene claro que el Yo no es algo dado, sino que debe estar en creación constante. Esto lo evidencia una cita de los años de la escritura de Aurora.

Es simple mitología creer que podremos encontrar nuestro auténtico Yo después de dejar esto y aquello [...] en cambio debemos construirnos a nosotros mismos, crear una forma a partir de todos los elementos: ¡Esa es nuestra tarea! ¡Constantemente la de un escultor! ¡La de un hombre productivo! ¡Nos convertimos en nosotros mismos no a través del conocimiento, sino de la práctica y de un modelo a seguir! El conocimiento, en el mejor de los casos, sólo tiene el valor de un medio. ${ }^{25}$

La filosofía de Nietzsche en su fase de espíritu libre es una respuesta a la constatación de la Muerte de Dios. Está totalmente dedicada a la problemática del arte de la vida, sobre el que reflexiona y que busca practicar. El planteamiento general del arte de la vida es comple-

${ }^{22}$ KSA 3, FW §299, p. 538.

${ }^{23} \mathrm{KSA} 3, \mathrm{FW} \S 366$, p. 615.

${ }^{24} \mathrm{KSA} 3, \mathrm{M} \S 178$, p. 157.

${ }^{25} \mathrm{KSA} 9$, fines de $1880,7[213]$, p. 361. 
mentado con la pregunta más precisa del cómo. Con ésta aborda los problemas de la constitución del sujeto, la relación con uno mismo y con el otro, la tarea de la práctica permanente, la posibilidad de la conformación de la vida individual y la reflexión sobre la muerte, sin las cuales la existencia pierde todas sus determinantes.

\section{Montaigne}

Que la teoría del arte de la vida no sólo surge como respuesta a la problemática nihilista de Occidente lo demuestra el ejemplo de Montaigne, quien a principios de la época moderna anticipadamente abordó en sus ensayos todos los temas del arte de vivir, vinculando su escepticismo de manera directa con las filosofías de la Antigüedad. No en vano durante la segunda fase de producción de Nietzsche, cuando éste se veía a sí mismo como un espíritu libre, Montaigne constituye su fuente principal de inspiración. En su tercera Consideración intempestiva, titulada "Schopenhauer como educador", Nietzsche construye un monumento a Montaigne y le dedica un sentido homenaje:

En términos de integridad, sólo conozco a otro escitor que ubico al mismo nivel, más arriba inclusive que Schopenhauer: y ése, es Montaigne. Que un hombre se haya puesto a escribir de esta manera incrementa verdaderamente las ganas de vivir en esta tierra. Yo, por lo menos, desde que conocí a este espíritu de sumo vigor y asombrosa libertad, me siento motivado a decir lo mismo que él dijo de Plutarco: 'Apenas lancé una mirada sobre él, y me crecieron piernas y alas. Si la tarea fuese hacer de esta tierra un lugar más hospitalario, me quedaría con él. ${ }^{26}$

La aparición de Montaigne en la historia de la moralística europea a principios de la Época Moderna constituye un verdadero acontecimiento, en tanto que, sin desechar la reivindicación salvadora del cristianismo, se vincula directamente en sus ensayos con los pensadores y poetas griegos y romanos de la Antigüedad, para interrogarlos sobre

${ }^{26}$ KSA 1, SE 2, p. 348. 
HERBERT FREY

las condiciones que se requieren a fin de alcanzar una vida dichosa. La centralidad del hombre en el cosmos y la idea de un Dios único y bondadoso no constituyen temas de reflexión para Montaigne. Sus famosos ensayos surgen de su distanciamiento del mundo y del poder. En términos metodológicos, son totalmente "circunstanciales". Su forma se desarrolló únicamente a lo largo de los años sobre la base de los apuntes con que solía acompañar sus lecturas. Montaigne fue el primero en denominar a este tipo de prosa reflexiva como "ensayo", es decir, literalmente intentos, que a partir de un motivo casual y de modo asistemático examinan un ámbito de la experiencia humana.

En el centro de los ensayos de Montaigne se encuentra el individuo que, libre de ataduras sociales e ideológicas, se hace responsable de su propia existencia. De este modo configura al sujeto que dispone de manera autónoma la formación de su vida individual. La estética del arte de la vida, que en Nietzsche permanece propiamente vacía, se llena de contenido en Montaigne. Si bien éste se ubica en la tradición filosófica de la Antigüedad tardía, dentro de la cual sus autores favoritos son Séneca y Plutarco, a quienes dedica algunos de sus ensayos, estos pensadores antiguos sólo le sirven a Montaigne como referencia para desarrollar sus propias experiencias y observaciones individuales. Su moralística se basa en la auto-observación, dado que el propio Yo es el más asequible a la experiencia. El Yo constituye a sí mismo en el punto de partida de su moralística y le da el carácter de una instancia que le habla al lector con sus ensayos. "Todos me reconocen en mis libros $\mathrm{y}$, en mis libros, a mí”, ${ }^{27}$ escribió el pensador francés en su famoso ensayo sobre algunos versos de Virgilio.

El "Yo" de Montaigne no es objeto de grandes disquisiciones teóricas: se manifiesta en pensamientos muy concretos sobre la enfermedad, la muerte, la religión, la política y la cultura. Ajenas a la pretensión de un carácter absoluto como el de las religiones monoteístas, sus auto-observaciones son planteadas desde una posición escéptica, que parte de que no existe ninguna forma segura de conocimiento sobre

${ }^{27}$ Montaigne, Essais. Erste Moderne Gesamtübersetzung, 1998, Frankfurt, Hans Stilett, Eichborn (Libro 3, 5). 
el ser humano, sino más bien valores empíricos que deben ser examinados una y otra vez.

La imagen del hombre de Montaigne -y con ella se vuelve precursor de un arte de la vida moderno-se sitúa más allá de la interpretación cristiana del mundo y, simultáneamente, de sus esperanzas y promesas inherentes. Su propia interpretación apunta al hecho de que una vida dichosa también es posible sin estas expectativas. El hombre ya no es, como en el cristianismo, la cúspide de la creación, sino que se ubica en el mismo nivel que los animales, de los cuales puede aprender tanto como ellos de él. La razón, tan sobrevaluada por la tradición platónicocristiana, se vuelve para Montaigne tan sólo un atributo más del hombre y de ningún modo el más importante. Su función positiva no consiste en dominar la sensualidad del ser humano, sino en conciliar su totalidad consigo mismo y con la naturaleza. Con este planteamiento Montaigne se convierte en un precursor de la Ilustración, sobre todo de la francesa, cuya característica principal consiste, según Panajotis Kondylis, ${ }^{28}$ en la rehabilitación de la sensualidad. Como muy pocos filósofos antes y después de él, Montaigne concibió al hombre de manera consecuente como una unidad de cuerpo y mente. La postura de vida que expone puede considerarse como totalmente postnihilista y nietzscheana, pues consiste en la aceptación de la propia naturale$\mathrm{za}$, la tolerancia frente a otras culturas y formas de vida, la distancia frente a las exigencias del mundo y, ante todo, la preservación de la propia autonomía interna.

La aceptación del individuo por sí mismo, significa, sobre todo, la aceptación de su propia corporalidad y transitoriedad. En su conocido ensayo Filosofar significa aprender a morir, concibe a la vida consciente como la familiarización con la muerte. La enfermedad y la decadencia no son una desgracia, sino momentos de este proceso de familiarización. La aceptación de la muerte se convierte en la condición previa para que una vida pueda autodeterminarse en este mundo. "La reflexión sobre la muerte es también la reflexión sobre la libertad. Quien ha aprendido a morir, ha desaprendido a servir. Saber morir nos

\footnotetext{
${ }^{28}$ Panajotis Kondylis, Die Aufklärung... op. cit.
} 
libera de todo sometimiento y toda obligación. La vida ya no acarrea desgracias a aquel que ha comprendido que perder la vida no es una desgracia". ${ }^{29}$

La aceptación de uno mismo, empero, significa también la aceptación de la fragilidad y mortalidad propias en el sentido de una subordinación al eterno ciclo de la vida.

La postura de nuestro autor frente a la vida es manifiestamente hedonista, en el mejor sentido de la palabra: se refiere a la posibilidad del arte de la vida, al despliegue de las capacidades propias en beneficio de un goce moderado de la vida. Precisamente porque el tiempo de vida es limitado y los cimientos de la existencia humana son endebles, el hombre debería aprovechar el plazo que le queda para disfrutar sin culpa de las satisfacciones de la vida. En una época en que la ética del trabajo calvinista se extiende por Europa, Montaigne reivindica el ideal antiguo del ocio.

El tolerar y el aceptar caracterizan también la posición que el individuo debe asumir ante otros seres humanos y ante el mundo. La tolerancia de Montaigne se fundamenta en una postura escéptica, que se construye contra toda imposición de carácter absoluto sin importar si proviene de la filosofía o de la religión.

En el plano político no se involucra en ninguna guerra contra la religión establecida, es decir, contra el catolicismo. Montaigne relaciona la tolerancia individual con el conformismo social. Frente a la Iglesia sugiere una conducta que él mismo practica: un comportamiento ortodoxo en público, preservando al mismo tiempo la distancia y la autonomía interna.

En los ensayos de Montaigne se percibe a cada paso el impulso de preservar y ampliar la autonomía interna. Las dos inscripciones que hicieron famoso al Oráculo de Delfos, es decir, "Conócete a ti mismo" (Gnoti seauton) y "Nada en exceso" (Meden agan), constituyen el trasfondo de sus ensayos. El ocuparse de uno mismo, apartado de los asuntos y la actividad cotidianos, se convierte en el elemento central de una buena vida, tal como la entendían los antiguos; algo indispensable para darle un contenido al arte de la vida.

${ }^{29}$ Montaigne, Essais, op. cit., Libro 1, 20, p. 48. 
Dos ensayos concretamente, Sobre la vanidad y Sobre la soledad, son los que mejor dan idea del concepto que Montaigne tenía de una vida dichosa. En el primero de ellos, se prefigura con precisión la demanda de autonomía del espíritu libre de Nietzsche.

Procuro no necesitar de ninguna otra persona de manera apremiante. Qué destino tan lamentable y amenazador tener que depender de otro. Ni siquiera nuestro Yo, nuestro propio y más seguro refugio, nos otorga seguridad suficiente: no tengo nada mío más que a mí mismo, e inclusive esta posesión es incompleta y parcialmente prestada. ${ }^{30}$

Y un poco más adelante, en el mismo ensayo, Montaigne expone:

Por todos estos motivos, tengo una aversión mortal a comprometerme, directa o indirectamente, con alguien más que no sea yo mismo. Antes de recurrir por cualquier causa, importante o no, a la ayuda ajena, aplico toda mi energía para podérmelas arreglar sin ella [...] Una deuda de gratitud puede ser saldada en ocasiones, pero nunca totalmente borrada. Qué atadura tan terrible para alguien que ama tener libertad de movimiento en todas direcciones. ${ }^{31}$

La independencia es tan solo un elemento constitutivo del arte de la vida. Otro, el ocuparse de uno mismo, que sólo puede ser realizada en el aislamiento. El retiro de Montaigne en la torre de su castillo es la condición que hace posibles las reflexiones de sus ensayos.

En el ensayo Sobre la soledad, la apología de Montaigne de la autorreflexión y el ocuparse de uno mismo encuentran una expresión elocuente.

Tenemos que reservarnos un cuartito trasero, sólo para nosotros, donde nadie nos moleste, para hacer de este lugar de aislamiento nuestro retiro más importante, nuestro verdadero refugio. Aquí lo que importa es cultivar el trato cotidiano con nosotros mismos, dejarnos absorber por la soledad de tal manera que no quede espacio para el trato con otras perso-

${ }^{30}$ Op. cit., III, 10, p. 486.

${ }^{31}$ Ibid., III, 10, p. 487. 
HERBERT FREY

nas u otras cosas: es decir, que sostengamos un diálogo con nosotros mismos y que nos riamos como si no tuviéramos ni mujer ni hijos, ni bienes ni propiedades, ni vasallos ni criados, a fin de que si un día los perdemos, no constituya para nosotros ninguna novedad arreglárnoslas sin ellos [...] Habiendo ya vivido suficientemente para otros, vivamos por lo menos el último tramo de nuestra vida para nosotros mismos. Dirijamos nuestros pensamientos y nuestros propósitos hacia nosotros mismos y nuestro bienestar. No es una tarea fácil llevar a cabo nuestra retirada con toda tranquilidad; tenemos mucho qué hacer, para no vernos obligados después a aplicar medidas adicionales [...] hay que liberarse de esos vínculos tan fuertes y, de ahí en adelante, amar a veces una cosa y a veces otra, pero no comprometerse con nada, más que consigo mismo [...] Lo máximo en el mundo es saber que uno se pertenece a sí mismo. ${ }^{32}$

La defensa de la soledad como condición sine qua non para una vida dichosa, es un concepto que Nietzsche encuentra precisamente en Montaigne, quien así se convierte en el representante de una forma de vida que más tarde el filósofo alemán habría de vincular con la idea de espíritu libre.

Aunque no puede satisfacer el desmedido reclamo de salvación del hombre ni cumplir su anhelo de eternidad, la estética del arte de la vida como respuesta al nihilismo moderno sí constituye una autoafirmación humana, en tanto que, al contrario de toda reivindicación dogmática y de carácter absoluto, se instituye sobre la responsabilidad del individuo frente a sí mismo. Ante los poderes omnímodos del mundo, el arte de la vida apuesta a la intensificación del momento, tal como lo condensa Gottfried Benn en un aforismo: "El mundo no es mi creación y la sabiduría no es mi penuria, por eso le aconsejo que intensifique sus momentos, porque la totalidad no es salvable". ${ }^{33}$

${ }^{32}$ Ibid., I, 39, pp. 125-26.

${ }^{33}$ Gottfried Benn, Obras completas, vol. 2, 1579, 2003. 